\title{
Limiares entre a dança e o teatro
}

Thresholds between dance and theater

MAGALHÃES, Carolina de Pinho Barroso ${ }^{1}$

\section{Resumo:}

O objetivo desse artigo é refletir sobre o limiar entre a dança e o teatro, dentro do contexto de hibridismo das criações atuais. Procura-se trazer como foco para a experimentação desse espaço ecótone ${ }^{2}$ diálogos entre propostas e pensamentos de Jerzy Grotowski e de autores e processos criativos da dança, confluindo esse encontro através do criador intérprete em um trabalho sobre si.

Palavras-chave: dança, teatro, trabalho sobre si.

Abstract:

The purpose of this paper is to reflect on the threshold between dance and theater, in the hybrid context of the current creations. It has the intention to focus on the space ecotone to experiment dialogues among proposals and thoughts of Jerzy Grotowski and other authors; also on the creative processes of dance, converging this meeting through the interpreter creator in a work on yourself.

Keywords: dance, theater, work on yourself
1. caroldepinho@hotmail.com. Pesquisadora e criadora em dança contemporânea, teatro físico, butoh e performance. Atualmente realiza Mestrado em Artes Cênicas na UFOP, na linha de pesquisa: Processos e Poéticas da Cena Contemporânea e Pósgraduação em Dança: Criação, Improvisação e Ensino na PUC Minas.

2. Ecótone é uma região de transição entre dois biomas diferentes. Nela encontramse espécies de ambos os biomas e, portanto, uma grande biodiversidade. 
Por que era que eu estava procedendo à-toa-assim? Senhor, sei? O senhor vai pondo seu perceber. A gente vive repetido, o repetido, e, escorregável, num minuto, já está empurrado noutro galho. Acertasse eu com o que depois sabendo fiquei, para de lá de tantos assombros... Um está sempre no escuro, só no último derradeiro é que clareiam a sala. Digo: o real não está na saída nem na chegada: ele se dispõe para a gente é no meio da travessia.

(João Guimarães Rosa, Grande Sertão: Veredas)

A cena contemporânea tem se pautado cada vez mais num hibridismo de linguagens, desenhando-se em um lugar de permeabilidade entre dança, teatro e performance. A partir do século XX o corpo retoma um lugar especial na cena teatral e muitas obras passam a ser realizadas através da construção de partituras corporais por criadores-intérpretes em um "imbricamento criador-criatura-obra" (Cohen, 1998, p. 24), onde uma dramaturgia corporal pautada, segundo o mesmo autor, pelas justaposições, fragmentos e não causalidades se interpõe a uma narrativa linear ou uma dramaturgia textual pré-estabelecida.

[...] antes da modernidade a realidade física do corpo permaneceu geralmente incidental no teatro. Disciplinado, treinado e moldado para a função da significação, o corpo não era nem um problema nem um tema autônomo do teatro dramático, no qual permaneceu, sobretudo, como uma espécie de "subentendido" (LEHMAN, 2007, p.332)

Há um rompimento com a primazia do texto sobre a qual o corpo do ator deveria estar a atuando na produção de mimesis e significado. "Não se trata de suprimir a palavra do teatro, mas de fazê-la mudar sua destinação, e sobretudo de reduzir seu lugar [...]”. (ARTAUD, 2006, p.80). Segundo Dias (2015), Artaud privilegiava o gesto e a intensidade à construção textual.

Fazer a linguagem articulada dominar a cena ou a expressão objetiva dos gestos e de tudo o que atinge o espírito através dos sentidos no espaço é voltar as costas às necessidades físicas da cena e insurgir-se contra suas possibilidades. (ARTAUD, 2006, p.78)

Antonin Artaud é considerado por Lehman (2007) um dos precursores do teatro pós-dramático. Artaud considera que a narrativa linear e o discurso articulado no teatro ocidental fazem com que os conflitos apresentados no drama permaneçam no domínio psicológico ou social, de forma que agem sobre um interesse moral, que segundo ele, não precisa da cena para se resolver. O autor privilegia a sensorialidade do corpo e as rupturas trazidas pela vivência desses aspectos.

O processo pós-dramático se dá no corpo, segundo Lehman 
(2007), acessando-o como lugar de presença e experimentação, não mais de representação e interpretação de significados. Dessa maneira altera-se o lugar do ator em cena: de reprodutor de técnicas e mimeses a favor de um personagem, o ator passa a investigar e desconstruir a si mesmo nos processos criativos, onde ocorre também uma desconstrução do personagem, influenciado pelo ator que se envolve em um trabalho sobre si.

Isso interdita toda representação ou interpretação placidamente apoiada no corpo como mero intermediário. O ator precisa se colocar. Valère Novarina afirma: "O ator não é um intérprete, porque o corpo não é um instrumento". Ele refuta a idéia de "composição" de um personagem dramático pelo ator e sustenta, em contrário, que "é a decomposição do homem que se dá sobre o palco".3 (LEHMAN, 2007, p.336)

A noção de "trabalho do ator sobre si mesmo" foi concebida pelo ator e diretor Constantin Stanislavki e relaciona-se ao uso da memória emotiva de experiências pessoais para a construção da cena. Essa pesquisa percorreu diversos caminhos culminando nas ações físicas nas últimas fases da pesquisa do diretor.

Antes de começar a me concentrar sobre um papel específico, antes de pensar na criação do círculo de atenção no qual tenho que fazer entrar estas ou aquelas "circunstâncias dadas" do papel, tenho primeiro que libertar a mim mesmo das diferentes crostas e capas de minha vida privada que carrego até o momento em que comecei o trabalho criativo. (STANISLÁVSKI, 1994: p.89)

Jerzy Grotowski, diretor polonês, aprofunda a pesquisa de Stanislavski acerca das ações físicas a partir da noção de impulso, desenvolvendo assim a via negativa, que busca não mais agregar técnicas com o objetivo de gerar impactos no inconsciente do espectador, mas eliminar bloqueios e resistências no corpo-memória ${ }^{4}$ do ator, cedendo espaço à passagem de seus impulsos.

Em sua dissertação Entre a Precisão e a Espontaneidade: Grotowski e os princípios pragmáticos no trabalho do Ator, Moraes (2008), afirma que na primeira fase de sua pesquisa o diretor acreditava que o ator deveria romper os padrões cotidianos de comportamento e expressar-se através de "signos" capazes de tocar o inconsciente coletivo, havia forte influência do teatro clássico ocidental. Essa pesquisa evoluiu para a chamada linha orgânica, onde se relacionam estrutura e espontaneidade e fluxo consciente-inconsciente, partindo da via negativa.

Não educamos um ator, em nosso teatro, ensinando-lhe alguma coisa: tentamos eliminar a resistência de seu organismo a este
3. Valère Novarina, Le Théatre des paroles. Paris, 1988, pp.22 e 24. (in LEHMAN, 2007, p.336)

4. Para Grotowski o corpomemória distingue-se da memória corporal, estando o primeiro mais relacionado aos impulsos e à organicidade e nascido do próprio movimento e o segundo relacionado à consciência e racionalidade. A partir da linha orgânica de sua pesquisa, com a qual trabalhamos, o diretor interessa-se pelo fluxo consciente-inconsciente, razão-emoção, pelo corpo-memória, e não pela partitura gerada pela via da racionalidade.

O ator apela à própria vida, não procura no campo da

"memória emotiva" nem no "se" (termos utilizados no método de Stanislavski). Recorre ao corpo-memória, não tanto à memória do corpo, mas justamente ao corpo-memória. E ao corpo-vida. Isso, eu chamo de "impulso". Cada ação física é precedida de um movimento subcutâneo que flui do interior do corpo, desconhecido, mas tangível. (GROTOWSKI, 1993, pg 24).

LIMA (2013) afirma que Grotowski trabalha com uma consciência orgânica onde o acesso a si é feito de modo "não conduzido, não manipulado e, portanto, não restrito pelo intelecto". 
processo psíquico. O resultado é a eliminação do lapso de tempo entre impulso interior e reação exterior, de modo que o impulso se torna já uma reação exterior. Impulso e ação são concomitantes: o corpo se desvanece, queima, e o espectador assiste a uma série de impulsos visíveis. Nosso caminho é uma via negativa, não uma coleção de técnicas, e sim a erradicação de bloqueios. (GROTOWSKI, 1992, p,14-15)

Dessa maneira, investe-se em um trabalho sobre si mesmo, que não diz de um "si" fixo, mas em constante transformação através da passagem de afetos. Na palestra "Trabalho sobre si mesmo em Grotowski e no Workcenter: novas formas de subjetividade, novos corpos", Tatiana Motta Lima afirma que o trabalho sobre si é feito em contato, e difere-se de um "mergulho em si egoísta e narcísico". Ela o identifica como um trabalho de resistência, no interior dos jogos de poder, no qual se faz necessário estar atento a subjetividades apegadas ao passado e a formas mecânicas de agir, sentir, pensar. Lima (2013) afirma que esse trabalho é uma "seta na direção do que é desconhecido e desejante em nós", e que "conhecer através da transformação de si é converter-se em diferente de si", portanto o trabalho se dá na direção do desconhecido, em uma zona de risco.

No teatro atual diversos autores e diretores têm praticado e investigado o trabalho sobre si como processo criativo. Quilici (2012, pg. 16) afirma que: "O ator é um sujeito que deve agir sobre si mesmo, transformando sua relação com o corpo e a subjetividade (memória, emoções, sensações, imaginação, vontade, etc)". Lehman (2007) cita variados processos que iniciaram uma libertação para uma expressividade, precisão e presença, dentre os quais de Jerzy Grotowski, Peter Brook, Eugênio Barba, Living Theatre.

Nesse processo o corpo ganha espaço bem como demais elementos da encenação, em suas expressividades particulares, investindo na potência criadora existente além do diretor e dramaturgo, mas também do ator, iluminador, cenógrafo, figurinista. Não entraremos nos demais elementos da cena, tendo como foco nesse artigo o corpo e a cena.

Concomitantemente a esse aprofundamento da intimidade do teatro com a corporeidade do ator criador, a dança vivencia um processo semelhante a partir de desconstruções de técnicas clássicas e padrões corporais e criativos fixados e também passa a direcionar um interesse crescente ao criador-intérprete. Enquanto o teatro se distancia da centralidade do texto como guia das criações e partituras corporais do ator, a dança questiona os padrões formais e estéticos de preparação de um bailarino reprodutor de técnicas e partituras e passa a interessar-se por sua potencialidade expressiva. 
Se antes o corpo movia-se verticalizado, alinhado e harmônico, em busca de um movimento ideal, estruturado por uma organização espacial geométrica estabelecida a priori como um jogo de regras fixas, na dança moderna o espaço passa a ser concebido a partir do corpo do bailarino, cujos movimentos ditam as direções e as fronteiras. [....] As primeiras gerações da dança moderna enfatizavam especialmente o papel expressivo do movimento. (PRIMO, 2006, p.105-106)

Ao narrar as transformações da história da dança Parra (2009) afirma que no século XVII, inaugura-se na Europa um sistema artístico codificado, tecnicamente elaborado através da dança clássica, surgida no reinado de Luis XIV na França. Há uma padronização dos corpos, preferencialmente magros e esguios, e as possibilidades criativas se inserem em um sistema de códigos delimitado. Para Robatto (1994, p. 48, apud Parra 2009) foi neste período que se iniciou uma separação das artes cênicas originalmente integradas: Teatro, Dança e Música e a consequente especialização de cada uma.

\begin{abstract}
Assim, a dança clássica acaba por herdar um brilhantismo gestual, parecendo não importar-se tanto com a expressão individual de cada bailarino, tornando-se a partir daí uma dança preocupada com o belo, com a aparência e com o externo, e todos estes princípios por vezes desprovidos de consciência sobre o seu devido significado. (...) No período referido acima, e até mesmo anos adiante, podemos pontuar a pouca importância dada ao que os bailarinos sentiam ou pensavam a respeito das criações que interpretavam. Podemos observar que no período que a dança passa hoje, procura-se o oposto dos bailarinos, que eles acima de tudo pensem, reflitam e tragam para as criações e para os movimentos as suas próprias indagações. (PARRA, 2009, p. 10-12)
\end{abstract}

No século XVIII, Jean-Georges Noverre inicia o interesse da dança pela subjetividade do bailarino. No século XX, a dança moderna inicia um questionamento sobre a rigidez das técnicas do balé clássico e em seguida a dança contemporânea questiona a padronização dos corpos e linguagens iniciando uma fusão de técnicas para a preparação do bailarino e abrindo espaço a corpos variados e outras possibilidades de dançar, incluindo a ausência da música e os micromovimentos.

Colaborando para esse ponto de vista, Greiner (2006 apud Garrocho, 2007) observa que uma das rupturas produzidas pela dança contemporânea seria a de que as técnicas não resultam no espetáculo, como ocorria, por exemplo, no Balé Clássico e na Dança Moderna. Na dança contemporânea o espetáculo, ao invés de trazer técnicas que são adquiridas e repetidas, nos mostra um corpo que é atravessado por uma questão, num meio produzido por uma pesquisa. Segundo Travi (2011), nesse 
momento os coreógrafos passaram a explorar a história e o imaginário pessoal dos bailarinos, transformando esse material em arte, mais especificamente, em movimento. O coreógrafo, dessa maneira, deixa de ser o profissional que ensina coreografias, para tornar-se um artista que edita essa confluência de linguagens: "Daí a proposta de se pensar o coreógrafo contemporâneo como sendo um DJ, isto é, um misturador autoral de materiais preexistentes." (KATZ, 1998, p.11).

Isadora Duncan, uma das precursoras da dança moderna nascente no final do século XIX e início do século XX, nega o formalismo do balé clássico no intuito de desenvolver uma dança onde a expressividade e originalidade do próprio corpo, inspirado em elementos da natureza, produzisse sua movimentação, não mais derivada de técnicas pré-estabelecidas.

A dança expressionista alemã, de acordo com Lima (2008), trabalhou com "estados de movimento" como instrumentos para a liberdade emocional, utilizados no lugar dos códigos de movimentos pré-determinados. A autora afirma que essa linguagem tornou possível a coexistência de duas tendências diferentes: "o tenso desejo em direção a uma forma - resultado de uma meticulosa construção das cenas - e a tentativa de trazer à tona os afetos subjetivos." (LIMA, 2008, p.50). Alguns coreógrafos se apropriavam de técnicas do balé clássico, como Marta Graham e Kurt Joss, outros encontravam novas vias para a pesquisa e composição, como Mary Wigman, Rudolf Von Laban e Yvonne Rainer.

Advindo desse movimento, o trabalho de Pina Bausch é retomado por Hercoles (2005) como um grande encontro entre técnica e expressividade. Através de perguntas variadas Pina solicitava aos bailarinos respostas que acessavam seu corpo-memória e afetos, através de movimentos, palavras, cantos, ou o que lhes proviesse. Gil (2005, p.173) narra a descrição da experiência de alguns bailarinos da cia de Pina Bausch:

Afirmam viver no seu interior experiências decisivas de "verdade", de "identidade", "experiências autênticas, profundas, pessoais". Quando estão em cena, é sua "verdade mais íntima" que se exprime. [...] É como se o "método Bausch" fizesse vir à superfície camadas soterradas de emoções e de sentimentos [...]

O Tanztheater de Pina Bausch, ao mesmo tempo em que aproxima a dança e o teatro, dá origem a uma discussão acerca das compreensões entre seus territórios e suas relações. Hercules (2005) critica a dualidade proposta pelo termo "dança-teatro ou teatro-dança", afirmando que o mesmo carrega um tipo de entendimento que perpetua a separação entre corpo e pensamento, e a fronteira entre a dança e o 
teatro: "O entendimento de que seu trabalho não é dança, sem dúvida, esbarra numa concepção que reduz a dança à simples coleção de passos arrumados coreograficamente." (Hercoles, 2005, p.104).

Para Gil (2005, p. 172), porém, seu trabalho promove uma ruptura de fronteiras:

[...] a arte de Pina Bausch faz correr um fio que serpenteia entre todos os gêneros de espetáculos (ou performances). [...] Porque a linha serpentina move-se e esse movimento de orla constitui propriamente a dança de Pina Bausch [...].

Esses movimentos vivenciados na dança e no teatro parecem promover uma reaproximação entre as linguagens através de um início de ruptura da dualidade entre corpo e mente, razão e emoção, forma e expressividade, e de um imaginário que associava a dança ao corpo, em uma estética da perfeição, e ao teatro o lugar do texto e da expressividade. Sobre essa dualidade, Eugênio Barba afirma que:

A tendência de fazer uma distinção entre dança e teatro, característica de nossa cultura, revela uma ferida profunda, um vazio sem tradição, que continuamente expõe o ator rumo a uma negação do corpo e o dançarino para a virtuosidade. Para o artista oriental esta distinção parece absurda, como teria sido absurda para artistas europeus em outros períodos históricos, para um bufão ou um comediante do século XVI, por exemplo. (BARBA, 1995, p. 12).

Ao analisar o percurso da dança e do teatro, Lehman (2007, p.339) sustenta que de fato tem havido essa aproximação entre as linguagens:

A dança é radicalmente caracterizada por aquilo que se aplica ao teatro pós-dramático em geral: ela não formula sentido, mas articula energia; não representa uma ilustração, mas uma ação. Tudo nela é gesto. Já se descreveu a transição da dança clássica para a moderna e em seguida para a pós-moderna como um deslocamento que - para usar as categorias da linguística- partiu do campo semântico para o sintático e então para o pragmático, isto é, o compartilhamento emocional de impulsos com os espectadores nas situações de comunicação do teatro. Esse deslocamento vale de modo geral para a manifestação do corpo no teatro pós-dramático.

Falkembac (2005) afirma que quando se trata da arte do ator-dançarino ${ }^{5}$, no âmbito da cultura ocidental, a produção corporal se encontra no limiar de uma fronteira criada culturalmente. Portanto, faz-se necessário compreender os pontos de encontros e rupturas entre a dança e o teatro e de fato vivenciar esse limar, dissolvendo suas fronteiras.
5. O termo atordançarino é originalmente utilizado por Rudolf von Laban (18791958), numa tentativa inicial de condensar o campo de pesquisa do corpo em cena. 
Dentro do contexto benjaminiano ${ }^{6}$ o limiar surge como uma zona de passagens, transições, transbordamentos, fluxos e espaços intermediários. Dessa forma, o limiar opõe-se à ideia de fronteira, que indica limite, cisão, separação precisa, pelo fato de ser considerado um espaço de maior porosidade (GAGNEBIN, 2010, p. 13). Limiar, portanto, é uma zona intermediária, que permite o trânsito e a permeabilidade entre lugares distintos, e muitas vezes opostos, uma chave para o que vem antes e o que vem depois.

A fronteira seria um espaço de limites definidos, que, segundo Gagnebin (2010, p.13) "contém e mantêm algo, evitando seu transbordar, mantendo definidos os contornos e limitações de um território". O limiar (soleira, umbral) distingue-se desse conceito por constituir um registro de movimento, "registro de ultrapassagem, de "passagens", transições. A autora afirma que na arquitetura o limiar permite o trânsito entre lugares diferentes, por vezes opostos.

Designa essa zona intermediária à qual a filosofia ocidental opõe tanta resistência, assim como o chamado senso comum também, pois, na maioria das vezes, preferem-se as oposições demarcadas e claras (masculino/feminino, público/privado, sagrado/profano etc.), mesmo que se tente, mais tarde, dialetizar tais dicotomias. (GAGNEBIN, 2012, p.15)

É necessário experienciar a deriva nesse espaço de liminaridade, vivenciar a potência dessa zona indeterminada, com o objetivo de criar porosidades nas fronteiras, torná-las permeáveis. Benjamin (2006, p.535) afirma que na vida moderna essas transições e ritos de passagem são pouco vivenciados: "Tornamo-nos pobres em experiências liminares (Schwllenerfabrungen)".

Se o tempo na modernidade - em particular no capitalismo- encolheu, ficou mais curto, reduzindo-se a uma sucessão de momentos iguais sob o véu da novidade (como no fluxo incessante de produção de novas mercadorias), então decorre daí uma diminuição drástica da percepção sensorial por ritmos diferenciados de transição, tanto na experiência sensorial quanto na espiritual e intelectual. As transições devem ser encurtadas ao máximo para não se "perder tempo". O melhor seria poder anulá-las e passar assim o mais rapidamente possível de uma cidade a outra, de um país a outro, de um pensamento a outro, de uma atividade a outra, enfim como se passa de um programa de televisão a outro com um mero toque na tecla do assim chamado "controle remoto", sem demorar inutilmente no limiar e na transição. O que se perdeu com esses novos ritmos (que podem também ter qualidades positivas) é aquilo que Benjamin, citando o grande antropólogo Arnold van Gennep, chama não só de passagem, mas de "ritos de passagem", título do livro de van Gennep. (GAGNEBIN, 2010, p.15)
6. Walter Benjamin é filósofo e sociólogo alemão. Na obra Limiares e Passagens em Walter Benjamim, produzida a partir do "Primero Colóquio Internacional do Núcleo Walter Benjamin: O Limiar", promovido pelo NWB (Núcleo Walter Benjamin) vinculado à Faculdade de Letras da UFMG, autores como Raul Antelo, Jeanne Marie Gagnebin e Wolgang Bock afirmam que os limiares e as passagens caracterizam a obra benjaminiana da Infância em Berlim por volta de 1900 até as Passagens, tematizando e questionando a delimitação dos espaços.

Compreende-se o mesmo como conceito fundamental para a compreensão da filosofia desse autor alemão. Dentro da fragmentação característica da obra de Walter Benjamin encontramos recortes e recorrências a esse tema, a partir dos quais, com o auxílio dos pesquisadores desse autor, que localizaram e precisaram suas ocorrências dentro da ampla produção teórica do mesmo, procuro trazer a compreensão de Walter Benjamin acerca do limiar, no intuito de associá-lo à cena contemporânea. 
Para transitar nessa zona de liminaridade Bock (2010, p.77) afirma que é importante "[...] uma predisposição específica do sujeito, que pode ser vista como um tipo de atenção particular." Faz-se necessário, portanto, ir contra as tentações de classificações apressadas, e disponibilizar-se à experimentação desses períodos de suspensão, hesitação.

[....] se trata de reconquistar para o pensamento os territórios do indeterminado e do intermediário, da suspensão e da hesitação, e isso contra as tentações de taxinomia apressada, que se disfarça sob o ideal de clareza. [...] de ousar pensar devagar, por desvio, sem pressupor a necessidade de um resultado ao qual levaria uma linha reta. (GAGNEBIN, 2010, p.16 -17)

O conceito de limiar é utilizado dentro dessa pesquisa pelo fato de a dança e o teatro estarem vivenciando um contexto de rompimento de fronteiras e ampliação de diálogos dentro da contemporaneidade. Percebe-se, portanto, a importância de que se vivencie a experiência do limiar, através de um cuidado ao relacionar conceitos, compreensões e práticas de cada uma dessas linguagens, revelando encontros e desencontros entre os referidos pontos de vista, de forma que não percam suas potencialidades nesse entrecruzamento. Agindo dessa maneira torna-se possível estabelecer fluxos de comunicação, e a partir deles, gerar novas reflexões acerca de contribuições de uma à outra linguagem dentro do contexto de hibridização da dança e do teatro contemporâneos. 
ARTAUD, Antonin. O Teatro e seu Duplo. São Paulo: Martins Fontes, 2006.

BARBA, EUGENIO e SAVARESE, NICOLA. A arte secreta do atorDicionário de antropologia teatral. Campinas: Hucitec, 1995.

BENJAMIN Walter. Passagens. Belo Horizonte: Editora UFMG, 2006. BOCK, Wolfgang. Atenção, fuga e salvação medila - duas figuras Iminares em rua de mão única, de Walter Benjamim. In Otte Georg, Seldmayer Sabrina e Cornelsen Elcio (org) Limiares e passagens em Walter Benjamin. Belo Horizonte, Editora UFMG, 2010.

BONFITTO, MATTEO. O ator-compositor: as ações físicas como eixo: de Stanislávski a Barba. $2^{\text {a }}$ edição. São Paulo: Perspectiva, 2006.

COHEN, Renato. Work in progress na cena contemporânea: criação, encenação e recepção. São Paulo: Perspectiva, 1998.

DIAS, L. Nietzsche, Artaud e o pós dramático: elementos de uma crise anunciada? Ensaios Filosóficos, Volume XI - Julho/2015.

FALKEMBACH, Maria Fonseca. Dramaturgia do corpo e reinvenção de linguagem: transcriação de retratos literários de Gertrude Stein na composição do corpo cênico. Florianópolis, UDESC/ CEART-Programa de Pós-Graduação em Teatro 2005 (Dissertação de Mestrado).

GAGNEBIN, Jeanne Marie. Entre a vida e a morte. In Otte Georg, Seldmayer Sabrina e Cornelsen Elcio (org) Limiares e passagens em Walter Benjamin. Belo Horizonte, Editora UFMG, 2010.

GIL, José. Movimento Total: O Corpo e a Dança. São Paulo: Iluminuras, 2005.

GREINER, Christine. O corpo artista e suas conexões indisciplinares. In: SEMINÁRIO DO PROJETO LABORATÓRIO: TEXTUALIDADES CÊNICAS CONTEMPORÂNEAS / AÇÃO ARTE EXPANDIDA. Curadoria de Fernando Mencarelli e Nina Caetano. Conferência. Teatro Francisco Nunes. Belo Horizonte: 25 de Agosto de 2006. In: GARROCHO, Luiz Carlos. MENCARELLI, Fernando Antonio. Cartografias de uma improvisação física e experimental. 2007. 228 f. : il.

GROTOWSKI, Jerzy. Em busca de um teatro pobre. 4 ed. Rio de Janeiro: Civilização Brasileira, 1992.

HÉRCOLES, Rosa Maria. Formas de Comunicação do Corpo Novas Cartas sobre a Dança. Tese Doutorado - Comunicação e Semiótica (PUC-SP), 2005.

KATZ, Helena. O coreógrafo como DJ. In: PEREIRA, Roberto; SOTER, Silvia(Orgs.). Lições de Dança 1. Rio de Janeiro: UniverCidade, 1998. Pag.11-24

LEHMANN, Hans-Thies. Teatro pós-dramático. Trad. Pedro Süssekind. São Paulo: Cosac \& Naify, 2007. 
LIMA, Carla Andréa Silva; HILDEBRANDO, Antônio. Dançateatro a falta que baila: a tessitura dos afetos nas obras do Wuppertal Tanztheater. 2008. 132f. Dissertação (Mestrado) Universidade Federal de Minas Gerais, Belo Horizonte, Escola de Belas Artes.

LIMA, Tatiana Motta. Habitações Provisórias. Palestra: Trabalho sobre si mesmo em Grotowski e no Workcenter: novas formas de subjetividade, novos corpos. http://vimeo.com/54158582, 2013.

MORAES, Alexander Evaristo Araújo; MENCARELLI, Fernando Antonio. Entre a precisão e espontaneidade: Grotowski e os princípios pragmáticos do trabalho do ator. 2008. 150 f. Belo Horizonte, MG. Dissertação (mestrado) - Universidade Federal de Minas Gerais, Escola de Belas Artes.

NIETZSCHE, Friedrich. A Origem da Tragédia (ou Helenismo e Pessimismo). Trad. Jacó Guinsburg. $2^{\mathrm{a}}$ ed. São Paulo: Cia. das Letras, 1992.

PARRA, Denise Vendrami. A Dança na Contemporaneidade: o foco em dois centros de formação. Lisboa: Universidade Técnica de Lisboa, 2009.

PRIMO, Rosa. A Dança Possível: as ligações do corpo numa cena. Fortaleza: Expressão Gráfica e Editora, 2006.

QUILICI, Cassiano Sydow. O Treinamento do Ator/Performer: Repensando o "Trabalho sobre Si" a partir de Diálogos Interculturais. Revista Urdimento, no. 19, Novembro 2012.

STANISLÁVSKI, K. Etica y disciplina/Metodo de acciones fisicas (Propedéutica del actor). Seleção e notas de Edgar Ceballos. México: Grupo editorial Gaceta, 1994.

TRAVI, Maria Tereza Furtado. A dança da mente: Pina Bausch e psicanálise. Porto Alegre: EDIPUCRS, 2011. 